\title{
Panel Data Stochastic Convergence Analysis of the Mexican Regions
}

\author{
Josep Lluís Carrion-i-Silvestre $^{\Omega}$ and Vicente German-Soto ${ }^{\Phi}$. \\ ${ }^{\Omega}$ IREA-AQR Group. Departament d'Econometria, Estadística i Economia \\ Espanyola. Universitat de Barcelona. \\ ${ }^{\Phi}$ Facultad de Economía, Universidad Autónoma de Coahuila. Unidad \\ Camporredondo Edificio “E”. Planta Baja, C.P. 25280. Saltillo, México
}

\begin{abstract}
The stochastic convergence amongst Mexican Federal entities is analyzed in panel data framework. The joint consideration of cross-section dependence and multiple structural breaks is required to ensure that the statistical inference is based on statistics with good statistical properties. Once these features are accounted for, evidence in favour of stochastic convergence is found. Since stochastic convergence is a necessary, yet insufficient condition for convergence as predicted by economic growth models, the paper also investigates whether $\beta$-convergence process has taken place. We found that the Mexican states have followed either heterogeneous convergence patterns or divergence process throughout the analyzed period.
\end{abstract}

Keywords: Stochastic convergence, $\beta$-convergence, nonstationarity panel data tests, cross-section dependence, multiple structural breaks.

JEL Codes: C12, C22, C32, O40, R11. 


\section{Introduction}

Panel data techniques have attracted the attention of most empirical practitioners that pursue better statistical inference through a combination of the information in both the cross-section $(N)$ and time $(T)$ dimensions. The increasing availability of statistical information has led to the application of panel-data-based statistics to sets of countries, sectors, regions or cities. An interesting feature that advocates the use of panel data techniques is that the time series are expected to share similar stochastic properties. This characteristic is even more likely to be found at regional level, where the individuals are exposed to common policies coming from national governments. If this is the case, taking into account both the cross-section and time series variation using a panel data approach might lead to an improvement in the statistical inference.

Macroeconomic panel data sets are characterized by having large time dimension, which implies that non-stationarity should be taken into account when conducting economic analyses if meaningful interpretations are to be obtained. This requires that the stochastic properties of panel data sets have to be assessed. In this regard, recent proposals in the econometric literature generalize unit root, stationarity and cointegration test statistics to panel data framework. These proposals differ depending on the degree of individual heterogeneity that is accommodated, the presence of cross-section dependence among individuals, and the stability of the parameters of the model, among other features - see, for instance, Banerjee (1999), Baltagi (2005), and Breitung and Pesaran (2007) for overviews of the field.

Although economic growth analysis has attracted the interest of many researchers, the studies that focus on developing countries from a regional point of view using panel data statistics are scarce. The aim of this paper is to fill this gap and increase the empirical evidence concerning income convergence for the Mexican regional case. Although there are some studies that deal with the Mexican regions - see Esquivel (1999), Cermeño (2001), and Carrion-i-Silvestre and German-Soto (2007) - none of them are based on the joint consideration of exploiting the information in the panel data set over a long period of time. Therefore and to the best of our knowledge, this is the first study that analyses the Mexican regional convergence phenomenon from a non-stationary panel data point of view. 
Some caution has to be taken when using non-stationary panel data statistics, since some of the proposals (the so-called first generation panel tests) assume that time series in the panel data are independent. The lack of consideration of the cross-section dependence might bias the analysis to conclude in favour of the stationarity of the panel data even in the case where it is non-stationary - see O'Connell (1998), and Banerjee, Marcellino and Osbat (2004, 2005). Fortunately, we can test the assumption of cross-section independence using the statistics in Pesaran (2004) and Ng (2006). In the case that these statistics point to the existence of crosssection dependence, we will then have to use panel data statistics (the so-called second generation panel tests).

The paper considers another relevant feature that is present in our data. Previous studies of the Mexican case - see, for instance, Chiquiar (2005), and Carrion-i-Silvestre and German-Soto (2007) - have revealed the existence of structural breaks that have affected the individual GDP in different ways - among the numerous events we can think of are the economic crises and reforms that took place in the eighties and nineties that so characterize the Mexican economic growth experience. These events might have changed the relationships of the economy as well as the convergence trends. It is well known that the presence of unattended structural breaks can bias the conclusions drawn from the application of unit root and stationarity statistics, both in univariate and panel data framework, concluding in favour of the unit root hypothesis - Perron (1989), Lee, Huang and Shin (1997), Montañés and Reyes (1998), and Carrion-i-Silvestre, del Barrio-Castro and López-Bazo (2002), among others.

Therefore, $-\mathrm{a}$ tension might appear when using panel data statistics, since unattended crosssection dependence might bias the analysis towards stationarity, whereas unattended structural breaks might bias the analysis towards non-stationarity. Consequently, the analysis has to consider both features. To this end, we compute the statistic in Carrion-i-Silvestre, del BarrioCastro and López-Bazo (2005) that accommodates the presence of multiple structural breaks and cross-section dependence among individuals. The analysis reveals that the joint consideration of both features points to the existence of stochastic convergence, though only for some states is $\beta$-convergence found.

The paper is organized as follows. Section 2 describes the methods and models that are used to study the presence of stochastic convergence. Section 3 introduces the econometric methodology and results of the stochastic convergence analysis amongst Mexican Federal 
entities. The presence of $\beta$-convergence is investigated in Section 4. Section 5 discusses the main economic implications for regional policies of the results. Finally, Section 6 concludes.

\section{Convergence hypothesis and panel-data-based tests: A brief overview}

Barro and Sala-i-Martin $(1991,1992)$ were the first who introduced the notion of $\beta$ and $\sigma$ convergence to assess whether the poor states (or countries) grow faster than the richer ones, implying that they will catch up ( $\beta$-convergence) in the long-run, or whether the dispersion of the income diminishes ( $\sigma$-convergence) over time. However, the econometric validity of these cross-section based approaches was questioned by Quah (1993), Carlino and Mills (1993), Bernard and Durlauf (1995), and Evans (1998), who defend the use of time series methods given that the cross-section approach is subject to bias (Quah, 1993).

Following Bernard and Durlauf (1995), $N$ economies are said to converge if, and only if, a common trend $a_{t}$ and finite parameters $\delta_{1}, \delta_{2}, \ldots, \delta_{N}$ exist so that

$$
\lim _{t \rightarrow \infty}\left(y_{i, t}-a_{t}\right)=\delta_{i},
$$

for $i=1, \ldots, N$, where $y_{i, t}$ denotes the real per capita income of the $i$-th time series. In order to account for the unobservable common trend, we define the average of the $N$ economies so that

$$
\lim _{t \rightarrow \infty}\left(y_{t}-a_{t}\right)=\frac{1}{N} \sum_{i=1}^{N} \delta_{i}
$$

where $y_{t}=N^{-1} \sum_{i=1}^{N} y_{i, t}$ denotes the average per capita GDP - the benchmark time series. If we define the level of the common trend so that $\lim _{t \rightarrow \infty}\left(y_{t}-a_{t}\right)=0$, and subtracting (2) from (1), stochastic convergence exists if, and only if,

$$
\lim _{t \rightarrow \infty}\left(y_{i, t}-\bar{y}_{t}\right)=\delta_{i} \text {. }
$$

In this framework, convergence is said to be absolute if, and only if, the unconditional mean $\delta_{i}=0$ in (3), while convergence is said to be conditional when $\delta_{i} \neq 0$ in (3). Bernard and Durlauf (1995) state that stochastic convergence occurs when per capita income of one economy relative to the benchmark economy is stationary, so we are therefore close to the steady-state. In this regard, stochastic convergence implies that idiosyncratic regional-specific factors cannot explain long-run economic growth and, moreover, that shocks to relative real 
per capita GDP have temporary effects. Thus, stochastic convergence implies that differences across economies are not persistent, and long-run movements in regional GDP are driven by common technology shocks (Evans, 1998).

In order to capture deviations from relative trend growth, Carlino and Mills (1993) propose to model deviations from the equilibrium $\left(\delta_{i}\right)$ as the combination of a time trend and a stochastic process:

$$
\delta_{i}=\mu_{i}+\beta_{i} t+u_{i} .
$$

Therefore, regional output $\left(y_{i, t}\right)$ is said to converge to the average of regional per capita output $\left(y_{t}\right)$ if $\left(y_{i, t}-y_{t}\right)$ is stationary. As pointed out in Carlino and Mills (1993), the specification given by (4) is a dynamic version of the Baumol hypothesis. Thus, $\beta$-convergence requires that if a region is initially above its compensating differential $\left(\mu_{i}\right)$, it should grow more slowly than the benchmark, which implies $\beta_{i}<0$ in (4). On the other hand, if the region is initially below its compensating differential, then $\beta_{i}>0$ in (4).

It is worth mentioning that although there are other approaches in the literature to analyze the presence of convergence - for instance, Quah (1996) studies the dynamic of the distribution, whereas Phillips and Sul (2007) use a non-linear factor model - in this paper we follow the approach in Carlino and Mills (1993), which relies on the application of unit root and stationarity statistics.

Empirical evidence based on univariate unit root and stationarity tests is not conclusive. Some papers often find convergence, while others conclude that GDP differentials persist and, therefore, economies diverge. On the one hand, Evans and Karras (1996) and Evans (1997) find stochastic convergence for the contiguous US states from 1929 to 1991, as well as for 54 countries using the Summers and Heston database from 1950 to 1990. On the other hand, Lee, Pesaran and Smith (1997) conduct convergence tests and find that steady-state growth rates differ substantially between the economies of 102 countries between 1960 and 1989. Some authors have argued that the lack of finding stochastic convergence may be driven either by the low power of univariate tests and/or by misspecification errors caused by unattended structural breaks. This has given rise to new analyses that consider either the presence of structural breaks on a country-by-country basis or the use of panel data statistics to increase the empirical power of unit root tests. 
Country-by-country analysis considering the presence of structural breaks can be found in Loewy and Papell (1996), and Tomljanovich and Vogelsang (2002), who confirm the evidence of convergence obtained in Carlino and Mills (1993) for the US regions. Smyth and Inder (2004) for the Chinese regions, DeJuan and Tomljanovich (2005), and Rodríguez (2006) for the Canadian regions, and Strazicich, Lee and Day (2004), and Dawson and Sen (2007) for some OECD countries, and Carrion-i-Silvestre and German-Soto (2007) for the Mexican regions, are some additional examples in the literature where the inclusion of structural breaks favours the finding of convergence.

Recently, panel-data-based unit root tests have been used to conduct stochastic convergence analysis. Fleissig and Strauss (2001) use panel data unit root tests concluding that real per capita GDP for OECD countries and one European sub sample converge in the period 19481987, but not in the entire sample of 1900-1987. Note that the fact of not accounting for the presence of structural breaks might be the reason why stochastic convergence is not encountered when focusing on the whole period. A similar situation is found in Pedroni and Yao (2006) for the Chinese regions, who conduct the analysis using panel data unit root tests with the definition of two sub samples. Pedroni and Yao (2006) conclude that there has been stochastic convergence for the 1978's Chinese pre-reform period, but not for the post-reform period.

Existing evidence that is based on the use of panel data unit root tests does not explicitly consider the presence of structural breaks, although previous analyses indicate that structural breaks might be affecting the time series that cover long periods. Therefore, the empirical approach that we undertake in this paper can be seen as a novelty that will prompt the development of further empirical analyses for other countries.

\section{Econometric methodology and results}

In order to investigate the presence of stochastic convergence amongst Mexican regions we compute panel-data-based unit root and stationarity statistics. We apply the panel data unit root based tests in Maddala and Wu (1999) - hereafter MW - and Im, Pesaran and Shin 
(2003) - henceforth IPS - as well as the panel data stationarity tests in Hadri (2000), which are suitable for panel data sets with moderate $N$ compared to $T$. The analysis tests the crosssection independence hypothesis that is assumed in all these panel data statistics. When this hypothesis is not satisfied, further statistics have to be computed to take account of the effects of cross-section dependence. Finally, we also consider the presence of multiple structural breaks, which is to be expected in our case given the previous studies in the literature that focus on the Mexican regional case.

The data set is the annual real per capita GDP for the $N=32$ Mexican regions during the period 1940-2001. Annual real GDP data set is provided in German-Soto (2005) and population data comes from INEGI (1999). We have investigated the presence of convergence using the difference between the logarithm of per capita real GDP in the Mexican regions $\left(y_{i, t}\right.$, $i=1, \ldots, N)$ and the logarithm of the national per capita real GDP $\left(y_{t}\right)$. Figure 1 depicts those relative income differences.

-- Insert Figure 1 here --

\subsection{Panel data unit root and stationary statistics}

The test in Im, Pesaran and Shin (2003) is based on the estimation of:

$$
\Delta y_{i, t}^{*}=f_{i}(t)+\delta_{i} y_{i, t-1}^{*}+\sum_{k=1}^{p} \gamma_{i, k} \Delta y_{i, t-k}^{*}+\varepsilon_{i, t},
$$

where throughout the paper $y_{i, t}^{*}=\left(y_{i, t}-\bar{y}_{t}\right)$ denotes the difference (in logarithms) between regional and national real per capita income, $f_{i}(t)$ denotes the deterministic component and $\varepsilon_{i, t}$ is assumed to be independently distributed across $i$ and $t, i=1, \ldots, N, t=1, \ldots, T$. It is worth noticing that throughout the paper we consider the deterministic specification that includes a linear time trend, since this specification is consistent with the definition of convergence as given in Carlino and Mills (1993). The null hypothesis is given by $H_{o}: \delta_{i}=0, \forall i$, whereas the alternative hypothesis $H_{l}: \delta_{i}<0$ for at least one $i$. Im, Pesaran and Shin (2003) propose the standardised group-mean Lagrange Multiplier $(L M)$ bar test statistic - denoted as $\Psi_{\overline{L M}}$ - and the standardised group-mean $t$ bar test statistic - denoted as $\Psi_{\bar{t}}-$ to test the null hypothesis of panel data unit root, which are shown to converge to the standard Normal distribution. Besides, Maddala and $\mathrm{Wu}(1999)$ propose combining the individual p-values $\left(\pi_{i}\right)$ associated 
with the pseudo $t$-ratio for testing $\delta_{i}=0$ in (5). The test is given by $\mathrm{MW}=-2 \sum_{i=1}^{N} \ln \left(\pi_{i}\right)$, which under the null hypothesis is distributed according to MW $\sim \chi_{2 N}^{2} \cdot{ }^{1}$

Evidence of panel data unit root tests can be complemented with the computation of stationarity tests. In this concern, Hadri (2000) provides a panel statistic where the null hypothesis is stationarity. The test in Hadri (2000) assumes that the individual time series $y_{i, t}^{*}$ is generated according to the following unobserved component model:

$$
\begin{gathered}
y_{i, t}^{*}=f_{i}(t)+r_{i, t}+\varepsilon_{i, t} \\
r_{i, t}=r_{i, t-1}+u_{i, t},
\end{gathered}
$$

where $f_{i}(t)$ can be either a constant or a linear time trend, $\varepsilon_{i, t}$ is assumed to be a stationary process and $u_{i, t} \sim \operatorname{iid}\left(0, \sigma_{u, i}^{2}\right) \forall i, i=1, \ldots, N$, with $\varepsilon_{i, t}$ and $u_{i, t}$ being mutually independent. In order to test the null hypothesis of stationarity Hadri (2000) proposes using the panel version of the test in Kwiatkowski, Phillips, Schmidt and Shin (1992) applied in the univariate context - hereafter KPSS test. In its heterogeneous version, the test statistic is given by:

$$
\eta_{k}=N^{-1} \sum_{i=1}^{N}\left(\omega_{i}^{-2} T^{-2} \sum_{t=1}^{T} S_{i, t}^{2}\right),
$$

$k=\{\mu, \tau\}$, where $S_{i, t}=\sum_{j=1}^{t} \hat{\varepsilon}_{i, j}$ denotes the partial sum process obtained from the estimated OLS residuals when regressing the individual time series on a constant $-\eta_{\mu}$ test - or on a time trend $-\eta_{\tau}$ test. Under the null hypothesis of stationarity, Hadri (2000) shows that the standardized test statistic given in (7) converges to the standard Normal distribution. We define $\hat{\omega}_{i}^{2}$ as a consistent estimate of the long-run variance of $\varepsilon_{i, t}, \omega_{i}^{2}=\lim _{T \rightarrow \infty} T^{-1} S_{i, T}^{2}, i=1$, $\ldots, N$. Note that the specification in (7) assumes heterogeneous long-run variances across individuals, although it is possible to impose homogeneity replacing $\hat{\omega}_{i}^{2}$ in (7) by

\footnotetext{
${ }^{1}$ In order to facilitate computation of $\pi_{i}$ we have carried out 100,000 replications to obtain the empirical percentiles for the ADF test for a DGP given by a random walk without drift. Then a response surface has been estimated to approximate the corresponding p-values using the logistic functional form given by:

$$
\pi_{i}=\frac{\exp \left\{z_{i} \beta\right\}}{1+\exp \left\{z_{i} \beta\right\}},
$$

where $z_{i} \beta=\beta_{0}+\beta_{1} x_{i}+\beta_{2} x_{i}^{2}+\beta_{3} x_{i}^{3}+\beta_{4} x_{i}^{4}$, with $x_{i}$ being the value of the ADF test and $\pi_{i}$ the corresponding percentile.
} 
$\hat{\omega}^{2}=N^{-1} \sum_{i=1}^{N} \hat{\omega}_{i}^{2}$. Carrion-i-Silvestre and Sansó (2006) compare different ways to estimate $\omega_{i}^{2}$ and suggest using the procedure described in Sul, Phillips and Choi (2005).

Results concerning the IPS, MW and Hadri statistics are reported in Table 1. Panel A in Table 1 offers the statistics that have been computed assuming that the individuals are cross-section independent. As can be seen, apparently contradictory conclusions are obtained from these statistics since, in general, the panel data unit root IPS and MW statistics allow the null hypothesis of unit root to be rejected, while the Hadri' statistics reject the null of stationarity. However, we have to bear in mind that rejection of the respective null hypotheses only means that some of the individuals are either stationary (in the case of the panel unit root tests) or non-stationary (in the case of the panel stationarity test). Furthermore, this inference is conditional to the fulfilment of the cross-section independence assumption, which can be tested using the developments in Pesaran (2004) and Ng (2006).

-- Insert Table 1 here --

\subsection{Testing the cross-section independence}

Pesaran (2004) designs a test statistic based on the average of pair-wise Pearson's correlation coefficients $\hat{p}_{j}, j=1, \ldots, n, n=N(N-1) / 2$, of the residuals obtained from ADF-type regression equations - this aims to isolate autocorrelation from cross-section dependence. The $C D$ statistic in Pesaran (2004) that tests the null hypothesis of cross-section independence against the alternative of dependence is given by

$$
C D=\sqrt{\frac{2 T}{n}} \sum_{j=1}^{n} \hat{p}_{j} \sim N(0,1)
$$

The approach in $\mathrm{Ng}$ (2006) relies on the computation of spacings to test the null hypothesis of independence. In brief, the procedure in $\mathrm{Ng}$ (2006) works as follows. First, we get rid of autocorrelation pattern in individual time series through the estimation of ADF-type regression equations. As for the test in Pesaran (2004), this allows us to isolate cross-section regression from serial correlation. Taking the estimated residuals from the ADF-type regression equations, we compute the absolute value of Pearson's correlation coefficients $\left(\bar{p}_{j}=\left|\hat{p}_{j}\right|\right)$ for all possible pairs of individuals, $j=1, \ldots, n$, where $n=N(N-1) / 2$, and sort them in ascending order. As a result, we obtain the sequence of ordered statistics given by 
$\left\{\bar{p}_{[1: n]}, \bar{p}_{[2: n]}, \ldots, \bar{p}_{[n: n]}\right\}$. Under the null hypothesis that $p_{j}=0$ and assuming that individual time series are Normal distributed, $\bar{p}_{j}$ is half-normally distributed. Furthermore, let us define $\bar{\phi}_{j}$ as $\Phi\left(\sqrt{T} \bar{p}_{[j: n]}\right)$, where $\Phi$ denotes the cdf of the standard Normal distribution, so that $\bar{\phi}=\left(\bar{\phi}_{1}, \ldots, \bar{\phi}_{n}\right)$. Finally, let us define the spacings as $\Delta \bar{\phi}_{j}=\bar{\phi}_{j}-\bar{\phi}_{j-1}, j=1, \ldots, n$.

In addition, $\mathrm{Ng}$ (2006) proposes splitting the whole sample $(W)$ of (ordered) spacings at arbitrary $\vartheta \in(0,1)$, so that we can define the group of small $(S)$ correlation coefficients and the group of large $(L)$ correlation coefficients. The definition of the partition is carried out through the minimization of the sum of squared residuals

$$
Q_{n}(\vartheta)=\sum_{j=1}^{\left[\vartheta_{n}\right]}\left(\Delta \bar{\phi}_{j}-\bar{\Delta}_{S}(\vartheta)\right)^{2}+\sum_{j=[\vartheta n]+1}^{n}\left(\Delta \bar{\phi}_{j}-\bar{\Delta}_{L}(\vartheta)\right)^{2},
$$

where $\bar{\Delta}_{S}(\vartheta)$ and $\bar{\Delta}_{L}(\vartheta)$ denotes the mean of the spacings for each group respectively. Consistent estimate of the break point is obtained as $\hat{\vartheta}=\arg \min _{\vartheta \in(0,1)} Q_{n}(\vartheta)$, where definition of some trimming is required - we follow $\mathrm{Ng}$ (2006) and set the trimming at 0.10 . Once the sample has been split, we can proceed to test the null hypothesis of independence in both sub samples. Obviously, the rejection of the null hypothesis for the small correlations sample will imply also rejection for the large correlations sample as the statistics are sorted in ascending order. Therefore, the null hypothesis can be tested for the small, large and the whole sample using the standardized Spacing Variance Ratio (SVR) in $\mathrm{Ng}$ (2006), which under the null hypothesis of independence converges to the standard Normal distribution.

The computation of the Pesaran's (2004) $C D$ statistic gives $C D=14.316$, which strongly rejects the null hypothesis of cross-section independence when compared to the standard Normal distribution. ${ }^{2}$ The same conclusion is reached by the application of Ng's (2006) statistic for the whole sample (7.800), for the small sample (6.301) and for the large sample (6.337). Furthermore, the feature that the $S V R$ statistic points to the existence of cross-section dependence when looking at the whole sample and both sub samples can be interpreted as an indication that cross-section dependence is pervasive, a feature that can be accommodated by the specification of approximate factor model such as those in Bai and $\mathrm{Ng}$ (2004). These

\footnotetext{
${ }^{2}$ In order to isolate the correlation, we estimate an ADF-type regression equation where the order of the model is selected using the $\mathrm{Ng}$ and Perron (1995) $t$-sig criterion with up to ten lags.
} 
elements indicate that panel data unit root and stationarity tests have to account for the presence of cross-section dependence.

\subsection{Panel data statistics with cross-section dependence}

Earlier proposals in the literature addressed the presence of cross-section dependence either including temporal effects (cross-section demeaning) - see Levin, Lin and Chu (2002), and Im, Pesaran and Shin (2003) - or through the computation of the empirical distribution by means of parametric Bootstrap - see Maddala and Wu (1999) for further details. In this paper we follow these two approaches and compute (i) the IPS, MW and Hadri statistics for the cross-section demeaned data, and (ii) the empirical Bootstrap distribution for the IPS, MW and Hadri statistics.

Recent developments have included the presence of the cross-section dependence in the model through the specification of approximate factor models - see Bai and Ng (2004), Moon and Perron (2004), and Pesaran (2007), among others. Since the proposal in Bai and $\mathrm{Ng}$ (2004) is the most general one, we compute here their statistics. The Bai and $\mathrm{Ng}$ (2004) approach decomposes the observable variables as follows

$$
y_{i, t}^{*}=f_{i}(t)+F_{t}^{\prime} \xi_{i}+e_{i, t},
$$

$t=1, \ldots, T, i=1, \ldots, N$, where $f_{i}(t)$ denotes the deterministic part of the model - either a constant or a linear time trend $-F_{t}$ is a $(r \times 1)$-vector that accounts for the common factors that are present in the panel, and $e_{i, t}$ is the idiosyncratic disturbance term, which is assumed to be cross-section independent. Unobserved common factors and idiosyncratic disturbance terms are estimated using principal components on the first difference model. The panel data unit root hypothesis on $\widetilde{e}_{i, t}$ can be tested using the idiosyncratic ADF statistic pooling the individual $p$-values. When the estimated number of common factors is $\hat{r}=1$, we can test the null hypothesis of unit root on $\hat{F}_{t}$ using the usual ADF statistic. Finally, when $\hat{r}>1$ we can use either the parametric or non-parametric MQ statistics suggested in Bai and $\mathrm{Ng}$ (2004) to estimate the number of common stochastic trends. The estimation of the number of common factors is obtained using the panel BIC information criterion in Bai and $\mathrm{Ng}$ (2002). 
Panel B in Table 1 presents the statistics for the cross-section demeaned panel data set. As can be seen, previous conclusions are unchanged since the null hypotheses of the IPS, MW and Hadri' statistics are strongly rejected. However, it is worth noticing that cross-section demeaning implies that cross-section dependence is driven by only one stationary common factor that has the same effect on all individuals. This situation is quite restrictive in practice, so that other ways to control for the presence of cross-section dependence have to be essayed. One alternative way to deal with cross-section dependence is the computation of the empirical distribution using Bootstrap techniques. Panel $\mathrm{C}$ in Table 1 reports the critical values for the statistics presented in Panel A of Table 1 - note that the null hypothesis is tested using the left tail for the $\Psi_{\bar{t}}$ statistic, and the right tail for the other statistics. Using these critical values, we conclude that the null hypothesis of non-stationarity cannot be rejected at the $5 \%$ level of significance for the IPS and MW statistics, while the null hypothesis of stationarity is strongly rejected with the Hadri' statistics. Therefore, these statistics lead to concluding against the existence of stochastic convergence.

This conclusion is reinforced when we model the cross-section dependence using the common factor approach in Bai and $\mathrm{Ng}$ (2004). Table 2 shows the panel data statistic that combines the individual ADF statistics for the idiosyncratic disturbance terms, as well as the MQ tests for the common factors with the specification of up to six common factors. Using these statistics we conclude that the null hypothesis of unit root cannot be rejected for the idiosyncratic disturbances. Furthermore, the MQ tests, either the parametric and non-parametric versions, point to the presence of six non-stationary common factors. It is worth noticing that the number of common factors, which has been estimated by the panel Bayesian information criterion (BIC) in Bai and $\mathrm{Ng}$ (2002), coincides with the maximum number of factors that is permitted - we have increased the maximum number of common factors, but it is achieved as well. This feature can be understood as evidence of unattended non-stationarity, being the presence of multiple structural changes a potential source.

-- Insert Table 2 here --

In all, the statistics that consider the presence of cross-section dependence in a general way indicate that stochastic convergence has not been taking place among the Mexican states during the analysed time period. However, this conclusion is not robust against the existence 
of multiple structural breaks, a feature that seems to be present in the data if we rely on previous analysis in the literature.

\subsection{Panel data statistics with multiple structural breaks}

We suggest the application of the statistic in Carrion-i-Silvestre, del Barrio-Castro and LópezBazo (2005), who extend the proposal in Hadri (2000) with the specification of the following deterministic component:

$$
f_{i}(t)=\alpha_{i}+\sum_{k=1}^{m_{i}} \theta_{i, k} D U_{i, k, t}+\beta_{i} t+\sum_{k=1}^{m_{i}} \gamma_{i, k} D T_{i, k, t}^{*}
$$

where $D U_{i, k, t}=1$ for $t>T_{b, k}^{i}$ and 0 elsewhere, $D T_{i, t, k}^{*}=t-T_{b, k}^{i}$ for $t>T_{b, k}^{i}$ and 0 elsewhere, with $T_{b, k}^{i}=\lambda_{i} T$ being the $k$-th break point for the $i$-th individual, $k=1, \ldots, m_{i}$, and $i=1, \ldots$, $N$, and $\lambda_{i} \in(0,1)$ denoting the relative position of the structural breaks (break fraction) for the $i$-th individual. The null hypothesis of stationarity is tested using the standardized statistic in (7), where the partial sum process is computed from the OLS residuals that are obtained using (8) - hereafter the panel statistic in Carrion-i-Silvestre, del Barrio-Castro and López-Bazo (2005) is denoted by $Z(\lambda)$, where $\lambda=\left(\lambda_{1}^{\prime}, \ldots, \lambda_{N}^{\prime}\right)^{\prime}$ collects the break fractions for all individuals. As can be seen, the deterministic specification given by (8) accounts for the presence of multiple structural breaks that affect either the level and/or the trend of the time series. In order to estimate the break points, Carrion-i-Silvestre, del Barrio-Castro and LópezBazo (2005) suggest applying the procedure first proposed in Bai and Perron (1998). The presence of cross-section dependence can be accounted for, either by cross-section demeaning or computing the empirical distribution by means of Bootstrap techniques.

\subsubsection{Break point estimation}

Provided that the variables that we are analysing show trending behaviour, the number of structural breaks have been selected using the modified Bayesian information criterion defined in Liu, Wu and Zideck (1997). The initial maximum number of structural breaks that we allow in our set-up is $m^{\max }=3$. However, in some cases this maximum is achieved, so that in order to ensure that there are no structural breaks left we increase $m^{\max }$ sequentially to $m^{\max }$ $=5$ or $m^{\max }=8$, depending on whether the maximum given by $m^{\max }$ is achieved. This sequential re-specification of the maximum number of structural breaks is adopted because 
the precision of the break point estimation drawn from the procedure in Bai and Perron (1998) depends on $m^{\max }$, i.e., the less $m^{\max }$, the more information is used to estimate the break points. Therefore, the increase of $m^{\max }$ and the consequent reduction in the amount of information that is used to estimate the break points can be understood as the price that we have to pay in order to ensure that we control for all possible structural breaks affecting each individual.

-- Insert Table 3 here -

Panel A in Table 3 presents the estimated number $(\hat{m})$ and position of the break points for each relative regional per capita income. The procedure detects one break for two individuals, two breaks for eleven individuals, three breaks in four cases, four breaks for eleven individuals, five breaks in two cases and, finally, six breaks in two cases. As can be seen, there is a high heterogeneity in the number and position of the break points among individuals.

Some estimated break points seem to respond to diverse events that affected either the whole Mexican economic activity (economic crises and reforms) or the economy of each Mexican region. For example, eleven of the detected break points are located around the crises of 1976, 1982, 1987 and 1994/1995, while three structural breaks are estimated in the period of the Mexican oil boom (between 1975 and 1986). Also, break points between 1982 and 1989 correspond to a convulse stage of the Mexican economy (high rates of inflation, unemployment and null rates of growth). Meanwhile, dates located before 1975 correspond to a stage of quick reduction of the per capita income differences.

We can carry out a more detailed analysis focusing on some of the Mexican states. For example, the estimates report only one break point for Quintana Roo. According to the estimated coefficients, Quintana Roo's real per capita income was converging from above to the national one in 1954, although from then on it has converged from below. Technically, the constant term fell to lower levels in that year. This result could be a consequence of mixed events. First, national GDP recorded an important increase (of about 10\%) in 1954 and, second, the tourism sector, which is Quintana Roo's main sector of economic activity, 
suffered an important income reduction in this period. As a consequence, Quintana Roo's relative income fell importantly. The Mexican oil boom, which occurred between 1975 and 1983, is also captured by the model. Campeche, Chiapas and Tabasco are the main oil producers of Mexico and the procedure has selected 1982, 1981 and 1981, respectively, as break points for these states. Data from the economic census of Mexico indicate than in those years oil production tripled. ${ }^{3}$

Four border states (Chihuahua, Nuevo León, Sonora and Tamaulipas) exhibited convergence from above and the other two border states (Baja California and Coahuila) exhibited divergence from above until their respective break point located in the eighties. After that, all border states (except Tamaulipas) diverge from above. This fact indicates that Border states have reaped most of the benefits from the trade reforms - after 1985 they exhibited an increasing tendency in their share of overall manufacturing employment, from $21 \%$ in 1985 to 34\% in 1998. Five break points are estimated for Distrito Federal (1949, 1960, 1970, 1983 and 1992). Up to 1983 Distrito Federal exhibited a uniform process of convergence from above, during 1983-1992 this state converged from below, and after 1992 the entity diverges from above. In this case we can see that in the period 1980-1988 the Mexico City region's share of manufacturing employment fell from $44.4 \%$ to $33.2 \%$, as a consequence of decentralization policies aimed to diminish over-population in the capital and the metropolitan area.

For the Southern states of Chiapas, Guerrero, Oaxaca, and Puebla we have estimated negative coefficients after their break points in 1990, 1987, 1983, and 1986, respectively. For these years one characteristic linking this group of states is found in their agricultural sector. Between 1984 and 1992 the prices of coffee and cocoa declined by more than $70 \%$ on international markets, primarily as a result of the dismantling of the International Coffee Agreement. It is estimated that subsistence income for small farmers in the Southern states of the Pacific Coast declined an average of $15 \%$ and that indigenous producers were one of the groups most severely affected by the decline in the price of coffee - as $65 \%$ of all coffee producers are indigenous and produce one-third of Mexico's coffee output. Furthermore, this

\footnotetext{
${ }^{3}$ Data from INEGI (1999) points out that in 1975 were extracting 261,589 (in thousands) barrels of oil, while in 1982 this quantity ascended to 1,002, 436 (also in thousands).
} 
is consistent with the finding that poverty incidence increased very sharply between 1984 and 1994 in the South of the country.

\subsubsection{Panel data statistics results}

Before proceeding to compute the panel statistic that combines the individual information, we have to assess whether time series are cross-section independent. As before, we base our inference on the Pesaran (2004) and Ng (2006) statistics. In order to isolate the correlation from the dependence issue, we have estimated an ADF-type regression equation that includes the dummy variables to capture the presence of the structural breaks estimated previously with up to five lags for the order of the autoregressive model. The order of the model is selected using the $\mathrm{Ng}$ and Perron (1995) $t$-sig criterion. The residuals from these regressions are used to compute the $C D$ statistic, which takes the value of $C D=7.269$ and, hence, when compared with the standard Normal distribution leads to a rejection of the null hypothesis of independence. This conclusion is also found by Ng's (2006) statistic both for the whole sample (5.202) and the large sample (4.004), although the null hypothesis of independence cannot be rejected at the 5\% level of significance for the small sample (1.291). Given that the proportion of statistics in the small group $(\hat{\theta}=0.4334)$ is smaller than the one for the large group, together with the result obtained by the $C D$ test, we can conclude that there is significant evidence of cross-section dependence. As mentioned above, this invalidates the inference drawn from the panel data statistics that assume cross-section independence - Table 3 offers these statistics for completeness.

Let us focus on the results that control for the presence of cross-section dependence. As the first approximation, we have proceeded to remove the cross-section mean to the individual time series and then computed the panel data statistic in Carrion-i-Silvestre, del Barrio-Castro and López-Bazo (2005). The results are reported in Panel B of Table 3, which indicate that the null hypothesis of stationarity is strongly rejected by both the homogeneous and heterogeneous long-run variance versions of the statistic. However, we should bear in mind that this approximation to remove the cross-section dependence is restrictive, so that other general ways to consider the cross-section dependence are essayed. In this regard, we have computed the empirical distribution of the statistic by Bootstrap techniques. Panel B in Table 3 offers the Bootstrap critical values. Note that if we compare the value of the $Z(\lambda)$ statistic, 
either computed using homogeneous $(Z(\lambda)=12.426)$ or heterogeneous $(Z(\lambda)=11.942)$ longrun variance, with the Bootstrap critical values the null hypothesis of stationarity cannot be rejected at the $5 \%$ level of significance.

To sum up, after the analysis has been controlled for the presence of multiple structural breaks and cross-section dependence, the results that have been obtained indicate that relative regional Mexican per capita incomes show stationary fluctuations around a broken trend, i.e., the study has found evidence of stochastic convergence. However, this sole evidence does not warrant the existence of convergence, since according to Carlino and Mills (1993) and Tomljanovich and Vogelsang (2002), actual convergence exists if stochastic convergence and $\beta$-convergence are verified.

\section{The analysis of $\beta$-convergence}

Our previous findings support the presence of stochastic convergence, a necessary, but not sufficient, condition to satisfy the definition of $\beta$-convergence. To do so, we follow Tomljanovich and Vogelsang (2002) and estimate the following equations for all the individuals:

$$
y_{i, t}^{*}=\sum_{k=1}^{m_{i}+1} \theta_{i, k} D U_{i, k, t}+\sum_{k=1}^{m_{i}+1} \gamma_{i, k} D T_{i, k, t}^{*}+u_{i, t}
$$

where now we define the regressors in an orthogonal way as $D U_{i, k, t}=1$ and $D T_{i, k, t}^{*}=t-T_{b, k-1}^{i}$ for $T_{b, k-1}^{i}<t \leq T_{b, k}^{i}$ and 0 elsewhere, with $T_{b, k}^{i}$ denoting the $k$-th previously estimated break point for the $i$-th individual, $k=1, \ldots, m_{i}$, with the convention that $T_{b, 0}^{i}=0$ and $T_{b, m_{i}+1}^{i}=T$, and $i=1, \ldots, N$.

Table 4 reports the estimated coefficients for each of the $m_{i}+1$ regimes, along with the corresponding statistics of significance computed using the Newey and West (1994) robust estimator of the covariance matrix. Looking at these estimates we can conclude that there has been $\beta$-convergence when the coefficients of the parameters of each regime are significant at least at the $10 \%$ level of significance and have opposite sign, i.e., either when $\theta_{i, k}<0$ and $\gamma_{i, k}$ $>0$, or when $\theta_{i, k}>0$ and $\gamma_{i, k}<0$ - using the notation in Tomljanovich and Vogelsang (2002), 
this situation is denoted as $C$. Similarly, we conclude that divergence has occurred when the coefficients of the parameters of each regime are statistically significant at least at the $10 \%$ level of significance and have the same sign, which is denoted in Tomljanovich and Vogelsang (2002) as D. It is possible to distinguish other interesting situations. Firstly, it would be possible that one of the parameters of the regime is not significant at the $10 \%$ level, but the other one is. In this case, we use $c$ to denote regimes consistent with $\beta$-convergence, but where only one of the two coefficients is statistically significant at the $10 \%$ level of significance. Similarly, we use $d$ to denote regimes consistent with divergence, but where only one of the two coefficients is statistically significant at the $10 \%$ level of significance. Secondly, Tomljanovich and Vogelsang (2002) characterize the situation in which both parameters are non-significant as the case where $\beta$-convergence has occurred so that we have achieved the equilibrium growth. This case is denoted by $E$. Table 5 summarizes the different situations corresponding to each regime. Note that Table 5 presents whether the states converge for different regimes, although the precise definition of these regimes has to be done using the information in Table 3. For instance, the first regime for Aguascalientes covers from 1940 till 1951, while the one for Baja California Norte goes from 1940 till 1962. The second regime for Aguascalientes goes from 1952 till 1960, while for Baja California Norte goes from 1963 till 1980.

-- Insert Tables 4 and 5 here --

In general, estimates suggest that $\beta$-convergence has taken part during the analysed period, although the process of convergence has not been uniform in all cases. For the first regime there was divergence in seven states (Chihuahua, Guanajuato, Hidalgo, Michoacán, Morelos, Sonora and Tlaxcala), equilibrium growth for one state (Campeche), and a $\beta$-convergence process in twenty-four out of the thirty-two states. For the last regime, $\beta$-convergence has only been achieved for Colima, eighteen states are consistent with divergence (Baja California N., Coahuila, Chiapas, Chihuahua, Distrito Federal, Durango, Guerrero, Hidalgo, Morelos, Nayarit, Nuevo León, Oaxaca, San Luis Potosí, Sinaloa, Sonora, Tlaxcala, Veracruz and Zacatecas), and only for thirteen states $\beta$-convergence is occurring. A similar analysis indicates that most of the convergence was achieved in the $1980 \mathrm{~s}^{4}$ Comparatively, for the

\footnotetext{
${ }^{4}$ The analysis is based in the prevalent regime at the beginning of the $80 \mathrm{~s}$.
} 
regimes in the 1980s we observe more states in equilibrium growth (2 to 1), less states in divergence (9 to 18 ) and more states in a convergence process (21 to 13) than the last regime. ${ }^{5}$ Figure 2 reflects this situation.

--Insert Figure 2 here -

Figure 2 suggests that border states were approaching the national income from above, while southern states were approaching from below in the 1980s. Results in this period widely contrast with those obtained in the first and last regimes, where some border states showed divergence from above and some southern states showed divergence from below. Figure 2 also highlights that all states that diverge from above to the national income are regions with high income levels (they are Sonora and Chihuahua, in the first regime, and Baja California N., Coahuila, Chihuahua, Distrito Federal, Nuevo León and Sonora, in the last regime), while nearly all of the states that diverge from below are regions with lower income levels (for example Hidalgo, Michoacán, Morelos and Tlaxcala, in the first regime, and Chiapas, Guerrero, Oaxaca and Tlaxcala, in the last regime). It suggests that only some of the relatively richer states had built the structure to take advantage of the new sources of growth derived from the enhanced opportunities to trade.

\section{Economic implications of the results}

Mexican regional income inequality is increasingly turning into a major political and social problem, which is basically manifested in two forms. First, relative economic stagnation, mainly in the South, makes it difficult for theses states to generate employment activities resulting in surplus labour migrating to the Centre and Northern states. This transient population is now seen as the source of a growing social problem. Second, Mexican experience suggests that trade policy plays an important role in determining regional economic fortunes. Therefore, if a reduction in inequality is a policy goal, then market reforms should, at least, have a regional perspective. Results indicate that major attention from the government to disadvantaged sectors or regions is required, so that income disparities can be reduced. Thus, note that interregional disequilibrium has not disappeared in

\footnotetext{
${ }^{5}$ The periods of each regime can be different amongst states. So, the analysis shows the evolution of the convergence process in each regime, although it does not imply that all states were converging at the same time.
} 
more than twenty years of free market economy. One way to solve this situation is the use of public investment policies as a redistributive instrument. This is an approach used in the case of the European regions with excellent results in regional growth and convergence (see, for example, Meliciani, 2006).

Looking at the results that we have obtained, it is possible to identify general patterns with important implications for regional policies. In those regions wherever the results suggest that break points have not been detected in the 1980s and 1990s (Baja California Sur, Coahuila, Colima, Jalisco, México, Michoacán, Querétaro, and Quintana Roo) the persistence of macroeconomic shocks would be smaller, so that stabilization policies are expected to be more effective. Two groups of states can be defined depending on the effects of the break points detected in the 1980s. First, we find those states - Baja California N., Campeche, Distrito Federal, Guanajuato, Nuevo León, Sonora, Tabasco, Tamaulipas and Yucatán - that improved their results after the break, suggesting that there is a continued role for government policies in addressing their structural problems given the finding of convergence and divergence from above. Second, we find those states - Chiapas, Guerrero, Hidalgo, Morelos, Nayarit, Oaxaca, Puebla, San Luis Potosí, Sinaloa, Tamaulipas, Tlaxcala, Veracruz, and Zacatecas - that worsened their performance after the structural break and for which macroeconomic policies seem not to be so effective in dealing with sudden shocks to real output.

Finally, we detect break points in Chiapas, Chihuahua, Distrito Federal, Durango, and Zacatecas during the 1980s and 1990s. In these cases the estimated break points can be indicating more sensibility to macroeconomic shocks than for other states. ${ }^{6}$ This finding suggests that government policy initiatives designed to promote economic development will result in changes in the trend until a new large shock occurs.

\section{Concluding remarks}

In this paper we have investigated the presence of stochastic convergence amongst Mexican Federal entities using long time series with panel-data based unit root and stationarity tests.

\footnotetext{
${ }^{6}$ Chiapas state is one exception because of the structural break in 1981 corresponding to the oil boom.
} 
The statistical evidence was conducted accounting for both the presence of cross-section dependence amongst panel units and the presence of multiple structural breaks. The paper has shown that there is strong dependence amongst the Mexican regions. Only after accounting for both multiple structural breaks and cross-section dependence, the relative per capita incomes showed stationary fluctuations around broken trend, i.e., stochastic convergence is found. However, this sole evidence does not warrant the existence of convergence, since, according to Carlino and Mills (1993) and Tolmjanovich and Vogelsang (2002), actual convergence exists if stochastic convergence and $\beta$-convergence are verified. The analysis of $\beta$-convergence confirmed that this process is occurring, although it has not been uniform in all cases. Real per capita income of the Mexican regions has been converging since 1940, but much of the convergence process occurred in the eighties, before the trade reform. From then on, convergence process has continued, although the intensity has been weaker than in the previous period.

The results have important implications for regional policies. In this regard, we have found that regions with high income levels (mostly of the Mexican North) are diverging from above, while nearly all of the states that diverge from below are regions with the lower income levels (mostly of the Mexican South). Moreover, after the trade liberalization, the income gap amongst rich and poor Mexican states is widening, one aspect that is increasingly turning into a major political and social problem for Mexico.

\section{References}

Bai, J. and S. Ng, 2002, Determining the Number of Factors in Approximate Factor Models, Econometrica, 70, 191-221.

Bai, J. and S. Ng, 2004, A PANIC Attack on Unit Roots and Cointegration, Econometrica, 72, $4,1127-1177$.

Bai, J., and P. Perron, 1998, Estimating and Testing Linear Models with Multiple Structural Changes, Econometrica, 66, 47-78.

Baltagi, B., 2005, Econometric Analysis of Panel Data. John Wiley \& Sons, Third Edition. Banerjee, A., 1999, Panel Data Unit Roots and Cointegration: An Overview, Oxford Bulletin of Economics and Statistics, Special issue, 607-629. 
Banerjee, A., Marcellino, M. and C. Osbat, 2004, Some Cautions on the Use of Panel Methods for Integrated Series of Macro-Economic Data, Econometrics Journal, 7, 2, 322-340. Banerjee, A., Marcellino, M. and C. Osbat, 2005, Testing for PPP: Should We Use Panel Methods?, Empirical Economics, 30, 77-91.

Barro R. and X. Sala-i-Martin, 1991, Convergence across states and regions, Brookings Papers on Economic Activity, 1, 107-158.

Barro, R. and X. Sala-i-Martin, 1992, Convergence, Journal of Political Economy, 100, 223251.

Bernard A. B., and S. N. Durlauf, 1995, Convergence in international output, Journal of Applied Econometrics, 10, 97-108.

Breitung, J. and M. H. Pesaran, 2007, Unit roots and cointegration in panels”. Forthcoming in Matyas, L., Sevestre, P., Eds., The Econometrics of Panel Data, Klüver Academic Press.

Carlino G. A. and L. Mills, 1993, Are U.S. regional incomes converging? A time series analysis, Journal of Monetay Economics, 32, 335-346.

Carrion-i-Silvestre, J. L., and A. Sansó, 2006, A guide to the computation of stationarity tests, Empirical Economics, 31, 433-448.

Carrion-i-Silvestre, J. L., and V. German-Soto, 2007, Stochastic Convergence amongst Mexican States, Regional Studies, 41, 531-541.

Carrion-i-Silvestre, J. L., T. del Barrio, and E. López-Bazo, 2005, Breaking the Panels. An Application to the GDP per Capita, Econometrics Journal, 8, 159-175.

Carrion-i-Silvestre, J. L., T. Del Barrio, and E. López-Bazo, 2002, Level Shifts in a Panel Data Based Unit Root Test. An Application to the Rate of Unemployment, Doct. Treball num. E02/79. University of Barcelona. http://www.ub.edu/ ere/ documents/ papers/ 79.pdf.

Cermeño, R., 2001, Decrecimiento y convergencia de los estados mexicanos. Un análisis de panel, El Trimestre Económico, 68, 603-629.

Chiquiar, D., 2005, Why Mexico's regional income convergence broke down, Journal of Development Economics, 77, 257-275.

Dawson, J. W. and A. Sen, 2007, New Evidence on the Convergence of International Income from a Group of 29 Countries, Empirical Economics, 33, 199-230. 
DeJuan, J. and M. Tomljanovich, 2005, Income convergence across Canadian provinces in the 20th century: Almost but not quite there, The Annals of Regional Science, 39, 567-592.

Esquivel, G., 1999, Convergencia regional en México, 1940-1995, El Trimestre Económico, $66,725-761$.

Evans, P., 1997, How Fast Do Economies Converge?, Review of Economics and Statistics, $79,219-225$.

Evans, P., 1998, Using Panel Data to Evaluate Growth Theories, International Economics Review, 39, 295-306.

Evans, P. and G. Karras, 1996, Convergence Revisited, Journal of Monetary Economics, 37, 249-265.

Fleissig A. R. and J. Strauss, 2001, Panel Unit-Root Tests of OECD Stochastic Convergence, Review of International Economics, 9, 153-163.

German-Soto, V., 2005, Generación del Producto Interno Bruto Mexicano por entidad federativa, 1940-1992, El Trimestre Económico, 72, 617-653.

Hadri, K., 2000, Testing for Unit Roots in Heterogeneous Panel Data, Econometrics Journal, $3,148-161$.

Im, K., M.H. Pesaran and Y. Shin, 2003, Testing for unit roots in heterogeneous panels, Journal of Econometrics, 115, 53-74.

INEGI, 1999, Estadísticas históricas de México, INEGI: Aguascalientes.

Kwiatkowski, D., P. C. B. Phillips, P. J. Schmidt, and Y. Shin, 1992, Testing the Null Hypothesis of Stationarity Against the Alternative of a Unit Root: How Sure are We that Economic Time Series Have a Unit Root, Journal of Econometrics, 54, 159-178.

Lee, J., C. J. Huang and Y. Shin, 1997, On Stationary Tests in the Presence of Structural Breaks, Economics Letters, 55, 165-172.

Lee, K., M. H. Pesaran and R. Smith, 1997, Growth and Convergence in a Multi-Country Empirical Stochastic Solow Model, Journal of Applied Econometrics, 12, 357-392.

Levin, A., C.F. Lin and J. Chu, 2002, Unit root tests in panel data: asymptotic and finitesample properties, Journal of Econometrics, 108, 1-24.

Liu, J., S. Wu and J. V. Zidek, 1997, On Segmented Multivariate Regressions, Statistica Sinica, 7, 497-525. 
Loewy, M. B. and D. H. Papell, 1996, Are U.S. regional incomes converging? Some further evidence, Journal of Monetary Economics, 38, 587-598.

Maddala, G. S. and S. Wu, 1999, A Comparative Study of Unit Root Tests with Panel Data and a New Simple Test, Oxford Bulletin of Economics and Statistics, Special Issue, 61, 631652.

Meliciani, V., 2006, Income and Employment Disparities Across European Regions: The Role of National and Spatial Factors, Regional Studies, 40, 75-91.

Montañés, A. and M. Reyes, 1998, Effect of a shift in the trend function on Dickey-Fuller unit root tests, Econometric Theory, 14, 355-363.

Moon, H. R. and B. Perron, 2004, Testing for unit root in panels with dynamic factors, Journal of Econometrics, 122, 81-126.

Newey, W. and K. West, 1994, Automatic Lag Selecion in Covariance Matrix Estimation, Review of Economic Studies, 61, 631-653.

Ng, S., 2006, Testing Cross-section Correlation in Panel Data Using Spacings, Journal of Business \& Economic Statistics, 24, 12-23.

$\mathrm{Ng}$, S. and P. Perron, 1995, Unit root tests in ARMA models with data dependent methods for the selection of the truncation lag, Journal of the American Statistical Association, 90, 268281.

O'Connell, P., 1998, The overvaluation of purchasing power parity, Journal of International Economics, 44, 1-19.

Pedroni, P. and J. Y. Yao, 2006, Regional Income Divergence in China, Journal of Asian Economics, 17, 294-315.

Perron, P., 1989, The Great Crash, the Oil Price Shock and the Unit Root Hypothesis, Econometrica, 57, 1361-1401.

Pesaran, M. H. 2004, General Diagnostic Tests for Cross Section Dependence in Panels, Cambridge Working Papers in Economics, No. 435, University of Cambridge, and CESifo Working Paper Series No. 1229.

Pesaran, M. H., 2007, A Simple Panel Unit Root Test in the Presence of Cross Section Dependence, Journal of Applied Econometrics, 22, pp. 265-312. 
Phillips, P. C. B. and Sul, D., 2007, Transition Modelling and Econometric Convergence Tests, Econometrica, 76, 1771-1855.

Quah, D. T., 1993, Empirical cross-section dynamics in economic growth, European Economic Review, 37, 426-434.

Quah, D. T., 1996, Convergence empirics across economies with (some) capital mobility, Journal of Economic Growth,1, 95-124.

Rodríguez, G., 2006, The role of the interprovincial transfers in the $\beta$ : Further empirical evidence for Canada, Journal of Economic Studies, 33, 12-29.

Smyth, R. and B. Inder, 2004, Is Chinese Provincial real GDP per capita nonstationary? Evidence from Multiple Trend Break Unit Root Tests, China Economic Review, 15, 1-24.

Strazicich, M. C., J. Lee and E. Day, 2004, Are incomes converging among OECD countries? Time series evidence with two structural breaks, Journal of Macroeconomics, 26, 131-145.

Sul D., P. C. B. Phillips and C. Y. Choi, 2005, Prewhitening Bias in HAC Estimation, Oxford Bulletin of Economics and Statistics, 67, 517-546.

Tomljanovich, M. and T. J. Vogelsang, 2002, Are U.S. Regions Converging? Using New Econometric Methods to Examine Old Issues, Empirical Economics, 27, 49-62. 
Figure 1. Relative regional per capita incomes

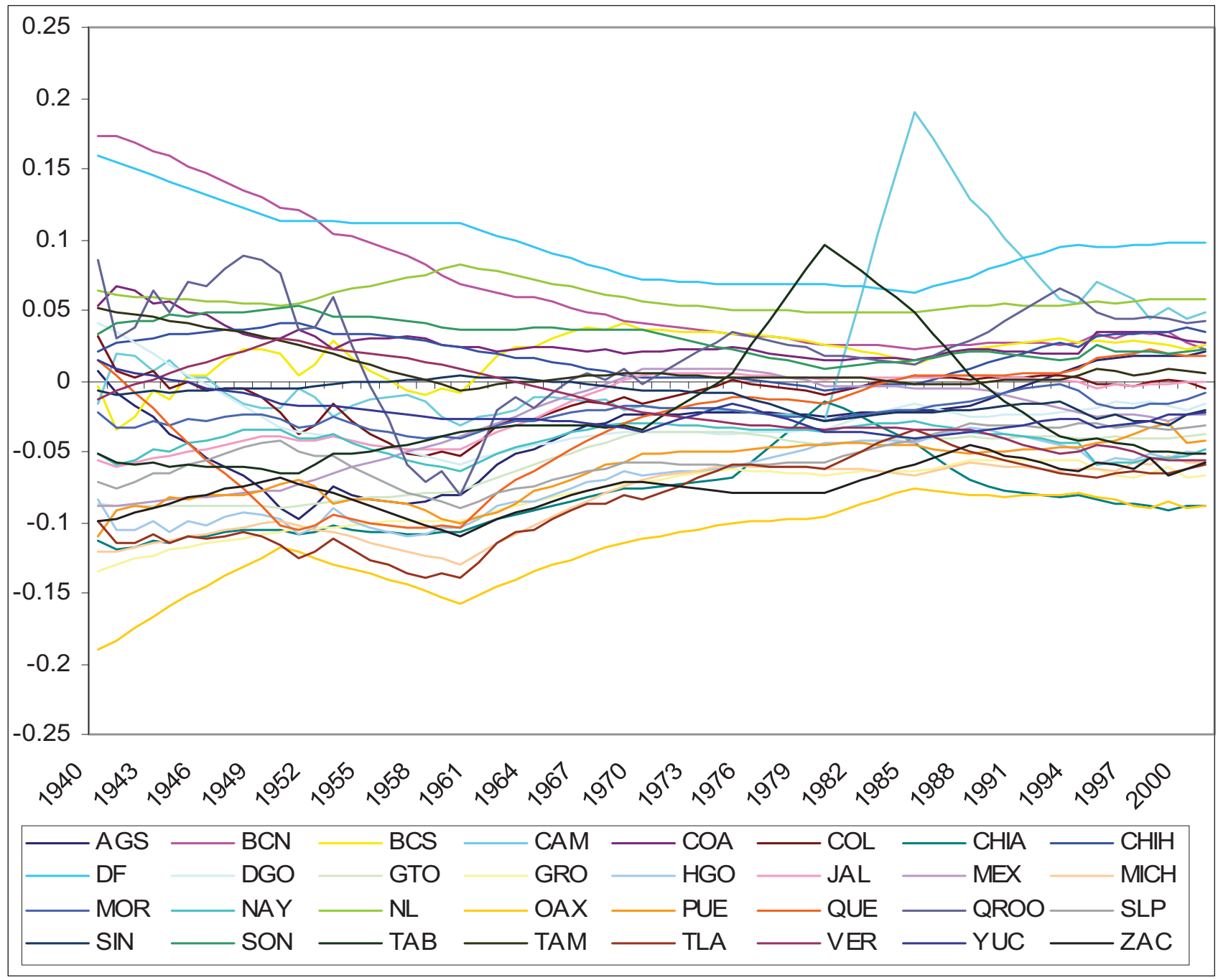


Figure 2. Map of the regional convergence and divergence

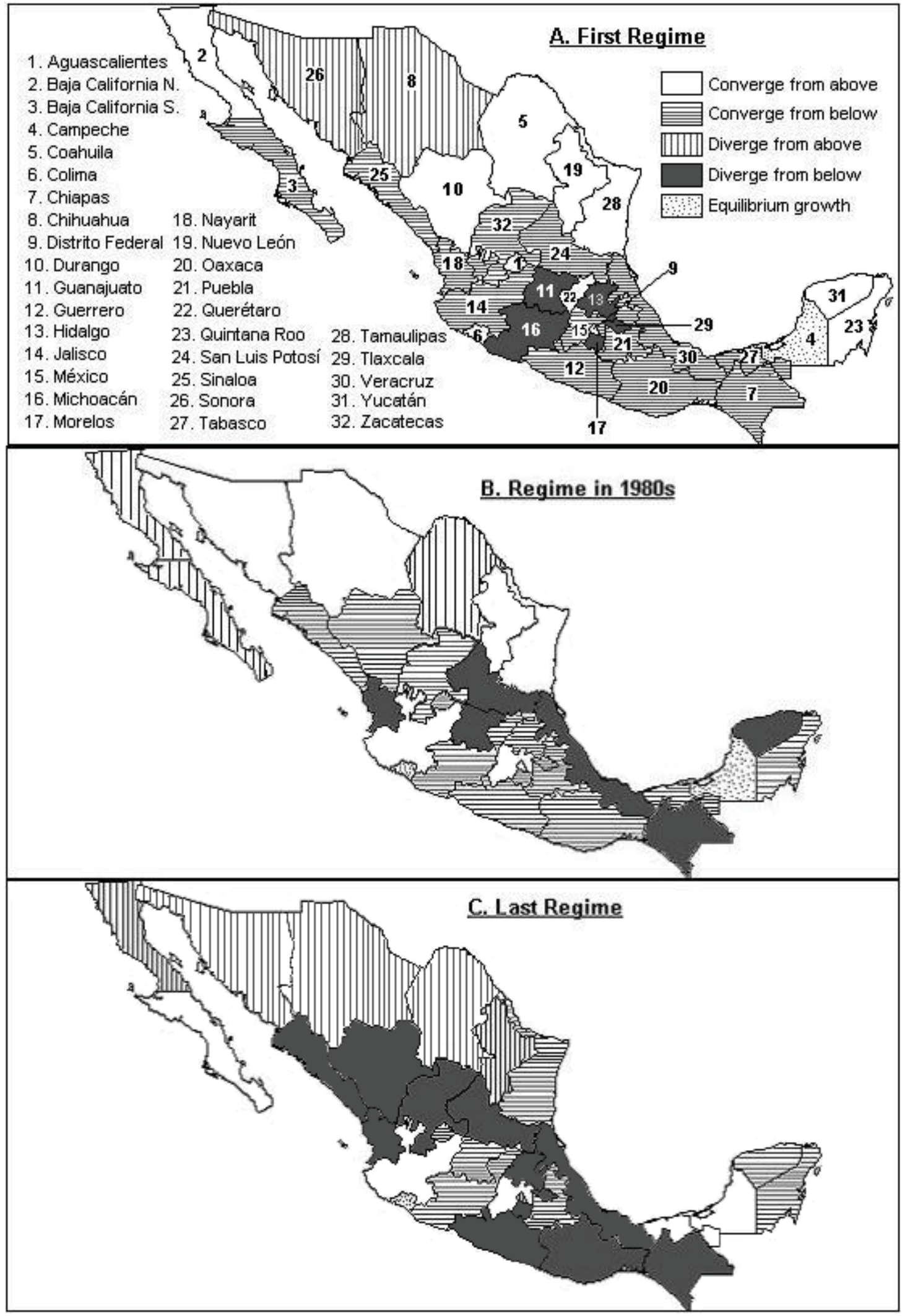


Table 1. IPS, MW and Hadri panel data statistics

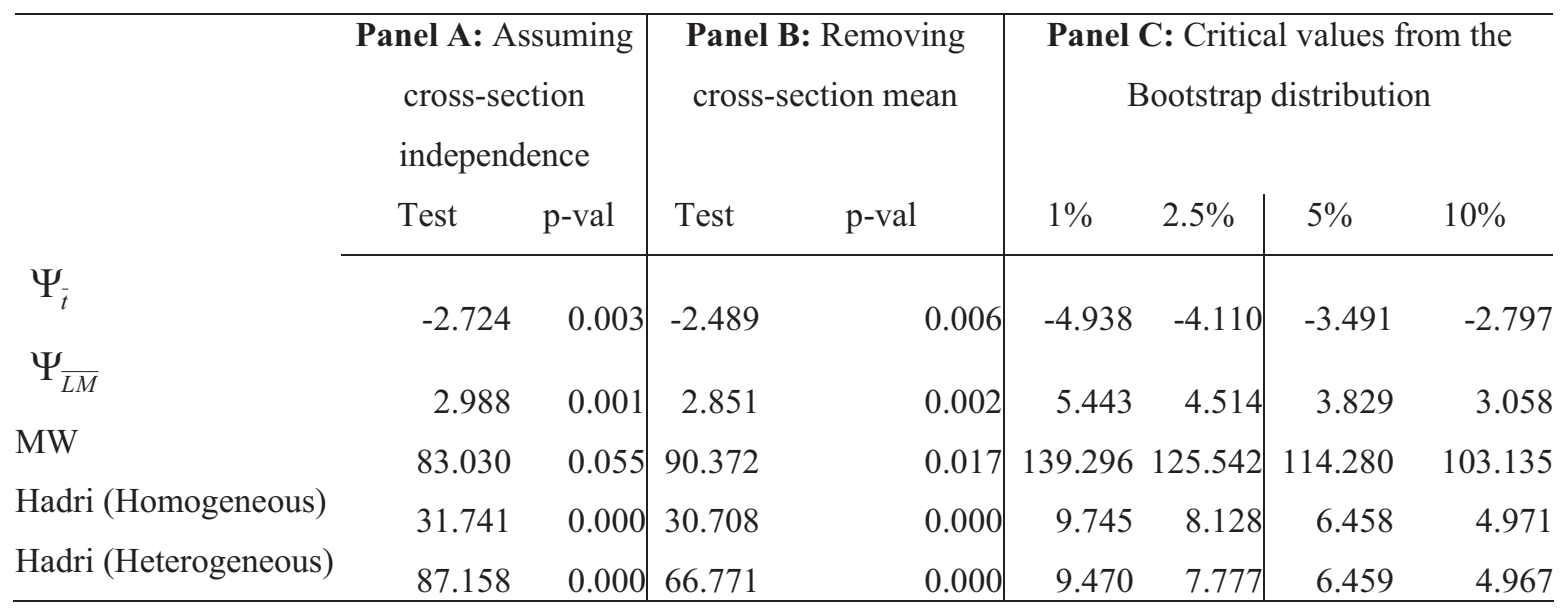

Note: Bootstrap distribution based on 2,000 replications

Table 2. Panel data unit root tests with common factors using Bai and Ng (2004) approach

\begin{tabular}{lccc}
\hline & Test & p-val & $\begin{array}{c}\text { Number of common stochastic trends } \\
\left(r^{\max }=6\right)\end{array}$ \\
\hline Idiosyncratic ADF statistic & 3.3636 & 0.999 & 6 \\
MQ_test (parametric) & -32.996 & & 6 \\
MQ_test (non-parametric) & -31.603 & & 6 \\
\hline
\end{tabular}


Table 3. Panel stationarity statistic with multiple structural breaks

\begin{tabular}{|c|c|c|c|c|c|c|c|}
\hline \multicolumn{8}{|c|}{ Panel A: Individual information } \\
\hline & $\hat{m}$ & $\hat{T}_{b, 1}$ & $\hat{T}_{b, 2}$ & $\hat{T}_{b, 3}$ & $\hat{T}_{b, 4}$ & $\hat{T}_{b, 5}$ & $\hat{T}_{b, 6}$ \\
\hline Aguascalientes & 4 & 1951 & 1960 & 1969 & 1988 & \multirow{17}{*}{$\begin{array}{l}1992 \\
1986\end{array}$} & \multirow{17}{*}{1995} \\
\hline Baja California Norte & 2 & 1962 & 1980 & & & & \\
\hline Baja California Sur & 2 & 1955 & 1969 & & & & \\
\hline Campeche & 1 & 1982 & & & & & \\
\hline Coahuila & 2 & 1953 & 1979 & & & & \\
\hline Colima & 2 & 1960 & 1975 & & & & \\
\hline Chiapas & 4 & 1956 & 1972 & 1981 & 1990 & & \\
\hline Chihuahua & 4 & 1950 & 1971 & 1983 & 1992 & & \\
\hline Distrito Federal & 5 & 1949 & 1960 & 1970 & 1983 & & \\
\hline Durango & 6 & 1950 & 1960 & 1967 & 1980 & & \\
\hline Guanajuato & 4 & 1951 & 1960 & 1970 & 1981 & & \\
\hline Guerrero & 4 & 1949 & 1961 & \multirow[t]{6}{*}{1975} & \multirow[t]{6}{*}{1987} & & \\
\hline Hidalgo & 2 & 1961 & 1989 & & & & \\
\hline Jalisco & 2 & 1957 & 1969 & & & & \\
\hline México & 2 & 1951 & 1971 & & & & \\
\hline Michoacán & 2 & 1957 & 1971 & & & & \\
\hline Morelos & 2 & 1962 & 1987 & & & & \\
\hline Nayarit & 4 & 1949 & 1960 & 1969 & 1982 & \multirow{12}{*}{1988} & \\
\hline Nuevo León & 4 & 1949 & 1959 & 1971 & 1985 & & \\
\hline Oaxaca & 4 & 1950 & 1960 & 1969 & 1983 & & \\
\hline Puebla & 4 & 1951 & 1960 & 1969 & \multirow[t]{3}{*}{1986} & & \\
\hline Querétaro & 3 & 1951 & 1963 & 1975 & & & \\
\hline Quintana Roo & 1 & 1954 & & & & & \\
\hline San Luis Potosí & 5 & 1950 & 1960 & 1969 & \multirow[t]{4}{*}{1979} & & \\
\hline Sinaloa & 3 & 1962 & 1977 & 1989 & & & \\
\hline Sonora & 3 & 1951 & 1967 & 1981 & & & \\
\hline Tabasco & 2 & 1969 & 1981 & & & & \\
\hline Tamaulipas & 4 & 1949 & 1960 & 1970 & \multirow[t]{2}{*}{1984} & & \\
\hline Tlaxcala & 2 & 1961 & 1987 & & & & \\
\hline Veracruz & 4 & 1950 & 1960 & 1973 & \multirow[t]{2}{*}{1989} & \multirow[b]{3}{*}{1987} & \multirow[b]{3}{*}{1994} \\
\hline Yucatán & 3 & 1951 & 1972 & 1985 & & & \\
\hline Zacatecas & 6 & 1949 & 1960 & 1968 & 1979 & & \\
\hline \multicolumn{8}{|c|}{ Panel B: Panel data statistics } \\
\hline & \multicolumn{2}{|c|}{$\begin{array}{l}\text { Cross-section } \\
\text { independent }\end{array}$} & \multicolumn{2}{|c|}{$\begin{array}{c}\text { Cross-section } \\
\text { demeaning }\end{array}$} & & \multicolumn{2}{|c|}{$\begin{array}{c}\text { Bootstrap } \\
\text { critical values }\end{array}$} \\
\hline & Test & p-val & Test & p-val & & $5 \%$ & $10 \%$ \\
\hline$Z(\lambda)$ Homogeneous & 12.426 & 0.000 & 3.200 & 0.001 & & 33.443 & 29.078 \\
\hline$Z(\lambda)$ Heterogeneous & 11.942 & 0.000 & 10.532 & 0.000 & & 22.917 & 21.406 \\
\hline
\end{tabular}

Note: Bootstrap distribution based on 2,000 replications 


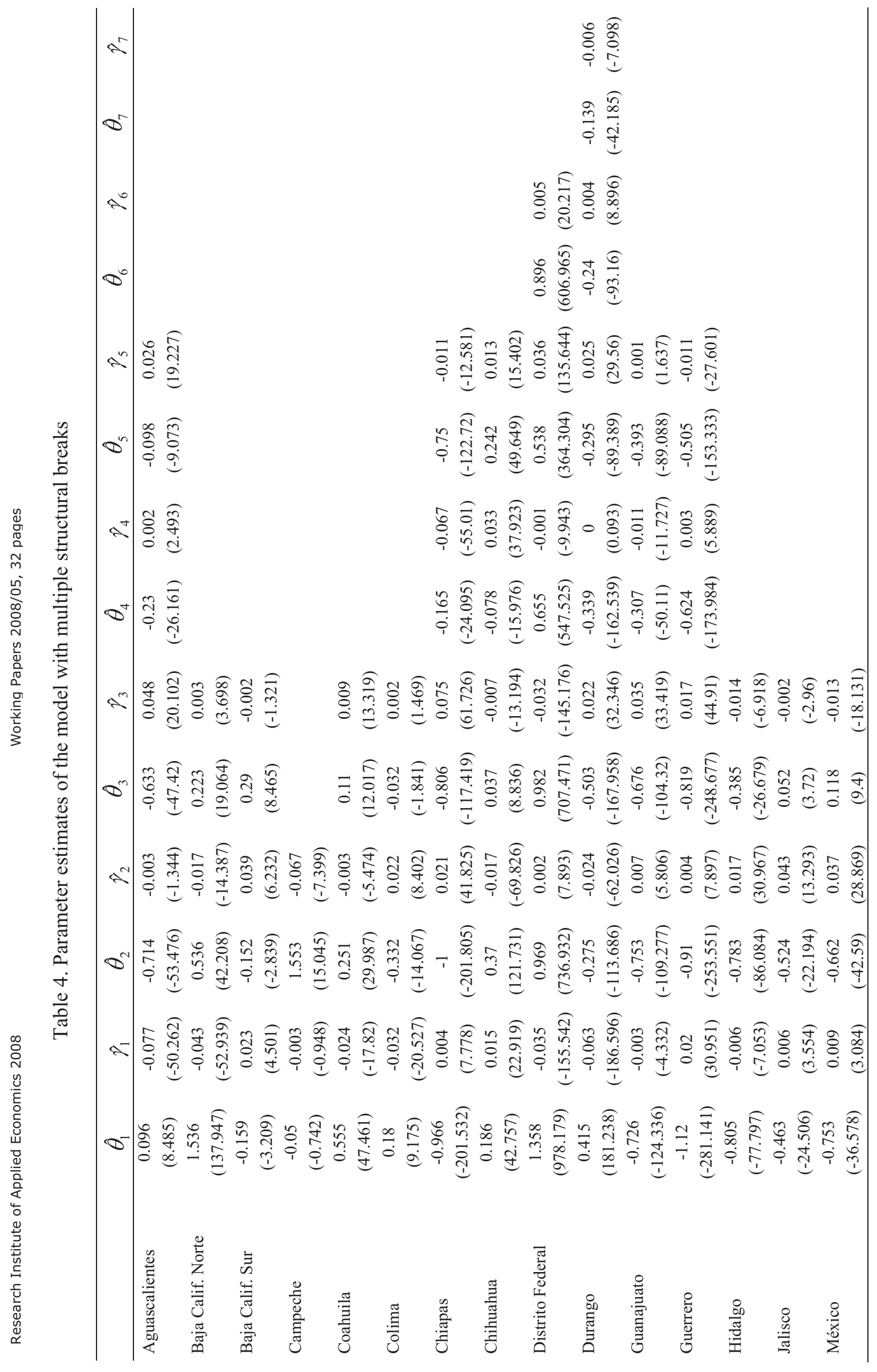




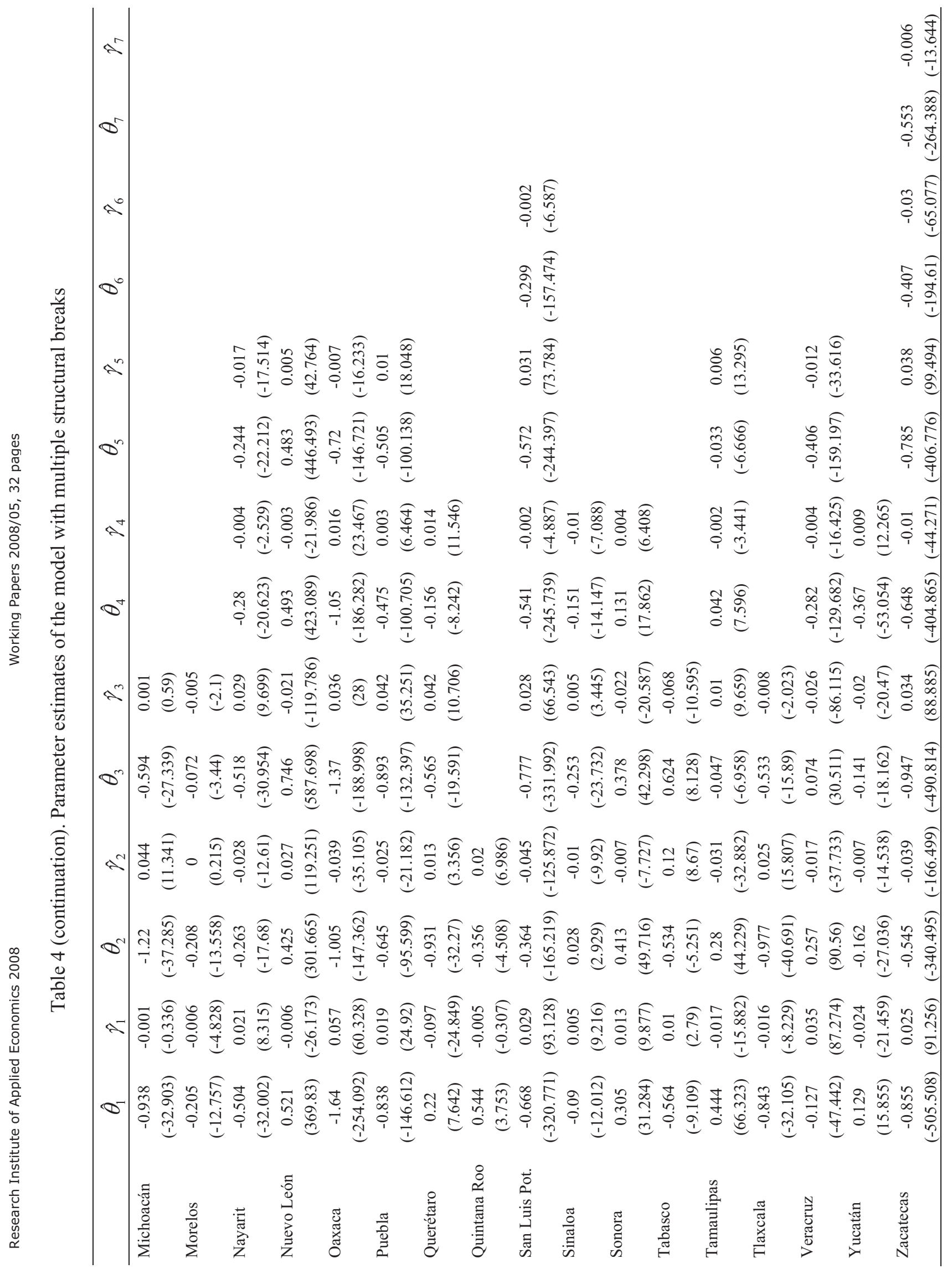




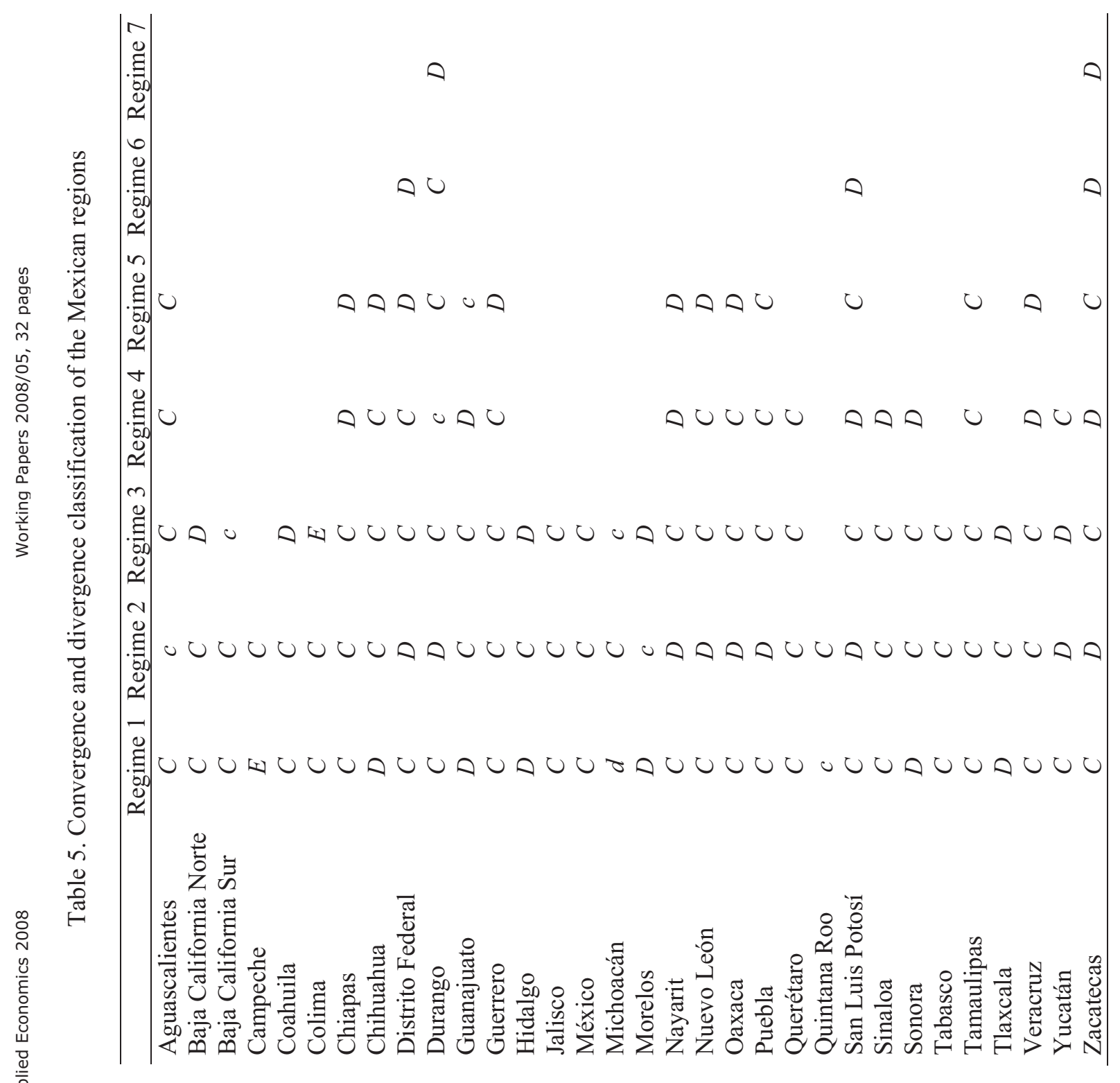

